\title{
LA EVOLUCIÓN HUMANA Y SU DIFUSIÓN EN ESPAÑA EN EL MARCO DE LA JAE (1907-1939)*
}

\section{Francisco Pelayo}

Instituto de Historia. CSIC

\section{RESUMEN}

Durante las primeras décadas del siglo XX se realizaron importantes hallazgos de restos fósiles de homínidos, que ampliaron el conocimiento sobre la Evolución Humana. Este período coincidió con el de actividad de la Junta para Ampliación de Estudios e Investigaciones Científicas (JAE), organismo que contribuyó a la difusión en España de los nuevos datos paleoantropológicos, mediante la dotación de becas de investigación, la creación de la Comisión de Investigaciones Paleontológicas y Prehistóricas (CIPP) y la financiación de las publicaciones de trabajos de Paleontología Humana.

PALABRAS CLAVE: Historia de la Evolución Humana, Historia de la Paleoantropología, Siglo $\mathrm{XX}$, España, JAE.

\section{THE DIFFUSION OF THE HUMAN EVOLUTION IN SPAIN AND THE JAE} (1907-1939)

\begin{abstract}
During the first decades of the 20th Century important findings of hominids fossil remains were made, enlarging the knowledge on Human Evolution. This period runs parallel to the activity of the Junta para Ampliación de Estudios e Investigaciones Científicas (JAE), an institution that helped to spread the new paleontological facts in Spain by providing funds for further studies and research, by the foundation of the Comisión de Investigaciones Paleontológicas y Prehistóricas (CIPP) and the promotion of publications on Human Paleontology.
\end{abstract}

KEY WORDS: History of Human Evolution, History of Paleoanthropology, 20th Century, Spain, Origins of the Mankind.

* Trabajo realizado en el marco del Proyecto I+D (MEC) HUM2006-04730/HIST 


\section{INTRODUCCIÓN}

El período de actividad de la Junta para Ampliación de Estudios e Investigaciones Científicas —JAE - (1907-1939), tuvo lugar en un contexto muy dinámico en el campo de las Ciencias Naturales. En estos años se fueron estableciendo las bases que terminarían por configurar en los años cuarenta una teoría de la evolución, la teoría sintética, con capacidad para de resolver problemas planteados por las limitaciones del darwinismo clásico y de otras orientaciones evolucionistas, como el neolamarckismo, el saltacionismo o la ortogénesis. Además, junto al surgimiento de la genética como disciplina científica, la sugerente propuesta de Alfred Wegener (1880-1930) de la deriva continental abrió una nueva perspectiva en los estudios paleobiogeográficos.

Asimismo, durante estas primeras décadas del siglo XX se realizaron importantes y continuos hallazgos de restos fósiles de homínidos que contribuyeron a ampliar el conocimiento que se tenía sobre la evolución humana. En este tiempo tuvieron lugar los debates sobre las leyes para la protección del patrimonio prehistórico y paleoantropológico, la expulsión del linaje humano de los neandertales, la presentación en la comunidad científica británica del fraudulento «hombre de Piltdown», y los descubrimientos del Australopithecus en Taung y Sterkfontein (Sudáfrica), del Sinanthropus en Zhoukoudian (conocida entonces como Chou-Kou-Tien, cerca de Pekín, China) y de nuevos restos de Pithecanthropus en Java. El problema radicó en que las interpretaciones sobre el árbol genealógico humano a partir de estos datos eran difíciles de encajar. La mayor parte de la comunidad angloamericana, apoyándose en el Eoanthropus de Piltdown, defendió la tesis de la gran antigüedad de la línea evolutiva humana, evitando la relación con antepasados antropoides y oponiéndose así a la aceptación del Australopithecus en la familia homínida. No fue hasta después de la II Guerra Mundial, que se superaron estos obstáculos epistemológicos, gracias al descubrimiento del fraude de Piltdown y la extensión de la teoría sintética de la evolución.

En este trabajo incidiremos en cómo fueron recibidos y divulgados en España, en el marco de actuación de la JAE, los nuevos datos paleoantropológi$\cos$ que fueron consolidando la configuración de una disciplina científica, enmarcada en la teoría de la evolución, encargada del estudio del origen y la antigüedad de la Humanidad. 
Durante el período de vigencia de la JAE, el escenario en que se desarrolló la Evolución Humana estuvo marcado por importantes hallazgos de fósiles, que establecieron una compleja situación en esta disciplina. Así, en las primeras décadas del siglo XX tuvo lugar en 1907 el hallazgo de una mandíbula humana de gran antigüedad en Mauer (Heidelberg). Poco después, se originó una polémica cuando el anticuario suizo germanófilo Otto Hauser (18741932) compró terrenos en el valle del Vèzere, lugar donde se habían encontrado los fósiles del hombre de Cromagnon, a fin de realizar excavaciones paleontológicas. De formación autodidacta, prescindió de la colaboración de prehistoriadores locales, a los que tildó de aficionados sensacionalistas y excursionistas domingueros, y solicitó en sus excavaciones la ayuda de antropólogos alemanes. Sin embargo, fue un prehistoriador alemán, Hugo Obermaier (1877-1946), que más adelante se asentaría en España, quien dirigió duras críticas a Hauser, cuestionando su capacidad científica, que le llevaba a destruir yacimientos, y reprendiendo su falta de escrúpulos para comerciar con los objetos excavados. Pero el clímax de la controversia llegó cuando Hauser vendió los esqueletos excavados en Combe Capelle y Le Moustier, al $\mathrm{Mu}$ seum für Volkerkunde de Berlín, en donde terminarían siendo expoliados durante la Segunda Guerra Mundial. La comunidad paleoantropológica francesa, encabezada por Marcellin Boule (1861-1942), profesor de Paleontología del Museum National d'Histoire Naturelle, emprendió una dura campaña contra Hauser y en favor de una ley nacional de protección del patrimonio prehistórico. Al iniciarse la Primera Guerra Mundial, Hauser, con su correspondencia intervenida y acusado de espía, se vio obligado a abandonar Francia, pasando sus propiedades rústicas a mano del Estado y recibiendo a cambio una mínima indemnización. Durante los años del conflicto bélico Boule reprodujo en la revista L'Anthropologie, artículos de periódicos locales franceses críticos con las noticias de diarios alemanes y de países neutrales como España (el artículo «Bárbaros» se publicó en El Correo del 30 de Diciembre de 1914), que defendían a Hauser. Este por su parte contribuyó a la polémica nacionalista, utilizando como anuncio propagandístico «El descubrimiento de dos esqueletos de hombres primitivos en un país enemigo», en la promoción de su libro Der Mensch von 100.000 jahren (1917).

En medio de la disputa por el affaire Hauser, unos clérigos franceses descubrieron el esqueleto neandertal de La Chapelle-aux-Saints. No sólo sirvió de excusa a la prensa nacionalista gala para exaltar el patriotismo, sino que el hallazgo fue reseñado por periódicos de todos los signos políticos, que insis- 
tieron en la importancia científica del fósil. Boule fue también protagonista en esta ocasión. En un ambiente dominado por la crisis del transformismo y el debate anticlerical, realizó una descripción anatómica del esqueleto muy controvertida y que terminaría recibiendo muchas críticas. Partiendo de sus preconcepciones, describió exageradamente al hombre de neandertal como un tipo simiesco y grotesco que caminaba con dificultad con las rodillas flexionadas, determinando así su expulsión de línea genealógica que conducía al Homo sapiens.

El rechazo del hombre de neandertal se enmarcó en una perspectiva paleoantropológica que tendía a considerar al desarrollo del cerebro como la primera fase del proceso que había llevado a la aparición del hombre. El surgimiento de esta orientación, que dominó y controló el desarrollo de la Paleontología Humana durante varias décadas, tuvo lugar en 1912, tras la presentación de los restos fósiles del fraude científico que, hasta el momento, más tiempo ha tardado en descubrirse. Tuvieron que pasar cuarenta años para que en 1953 oficialmente se reconociera que lo que se había proclamado como primer inglés, el Eoanthropus dawsoni de Piltdown, no era otra cosa que el fruto de un engaño o de una broma pesada, ya que en realidad estaba formado por el cráneo de un hombre moderno y la mandíbula de un orangután.

La tradición paleoantropológica británica que, basándose en la gran capacidad craneana del Eoanthropus atribuía una gran antigüedad a la época en que un «presapiens» de gran cerebro se desgajó del tronco común que compartía con los monos, fue asumida por paleontólogos como Henry F. Osborn (18571935). En este sentido, durante la década de los años veinte, Osborn, se opuso a la hipótesis del ancestro hombre-mono, considerada como la ortodoxia darwinista que defendía su colega William K. Gregory (1876-1970), con el que mantuvo una intensa polémica científica. Osborn sostuvo la existencia en el pasado de un proto-humano y un posterior Dawn Man, el primer hombre, que habría precedido la aparición del antepasado del hombre. Su preconcepción le llevó a apoyar, a partir de un diente fósil, la existencia de un imaginario Hesperopithecus, supuesto «hombre de Nebraska». Más adelante se demostró que el diente era de un pécari, mamífero emparentado con los cerdos.

Desde su cargo directivo del American Museum of Natural History, Osborn patrocinó y participó en las expediciones que partieron hacia las llanuras del Asia Central y el desierto de Gobi en busca del eslabón perdido. Pero, a pesar de los descubrimientos en los años veinte y treinta en China del $\mathrm{Si}$ nanthropus y en Indonesia del Pithecanthropus, Asia era sólo una de las posibles cunas de la Humanidad, cuestión que originó un extenso debate a lo largo de los siglos XIX y XX. El propio Darwin, al referirse al lugar de apari- 
ción del hombre y su antigüedad sobre la Tierra, había dicho que su origen no debía buscarse en Australia o en alguna isla cercana, sino en África. Pero apelando a datos etnográficos, antropológicos, paleontológicos, etc., todos los continentes fueron postulados como posible espacio donde había aparecido el hombre. Se propusieron lugares como la Patagonia, Siberia, Australia, la India, el Polo Norte, el Polo Sur, las llanuras al norte del Himalaya, África, Europa, el antiguo continente sumergido de Lemuria, etc., a los que habría que añadir las propuestas poligenistas, que defendía la existencia de muchas cunas, y la teoría de la hologénesis, según la cual la Humanidad habría aparecido simultáneamente en todo el globo terráqueo. Prácticamente hasta los importantes descubrimientos de restos fósiles de homínidos en África a partir de 1959, no se alcanzó un consenso entre los paleoantropólogos para considerar a este continente como la cuna de la Humanidad.

A pesar de todo, lo más grave no fue esta falta de consenso con relación a la cuna de la Humanidad, sino que durante estas décadas la aceptación del «hombre de Piltdown» como ancestro de los hombres modernos condicionó la aceptación de los nuevos hallazgos, como el del Australopithecus, descubierto en Sudáfrica en 1925 por Raymond Dart (1893-1980). En un principio, $\mathrm{y}$ aunque nuevos fósiles de este género fueron hallados posteriormente también en Sudáfrica por Robert Broom (1866-1951), este homínido no fue aceptado como tal entre la mayoría de paleoantropólogos hasta finales de la década de los cuarenta. El Australopithecus fue rechazado como antepasado del hombre ya que su cráneo pequeño e infantil, su incierta antigüedad y su procedencia africana, no entraba en el esquema de la evolución humana defendido por las principales autoridades y expertos en Paleoantropología de su época, Arthur Smith-Woodward (1864-1944), Grafton Elliot Smith (1871-1937) y Arthur Keith (1866-1955), que no eran otros que los científicos británicos defensores del hallazgo de Piltdown ${ }^{1}$.

\section{EL APOYO DE LA JAE A LOS ESTUdIOS DE EVOLUCIÓN HUMANA}

Uno de los factores en que se basó la política científica desplegada por la JAE en materia de investigación fue la de establecer un sistema de dotación

1 Véase Cohen, C. (2005), Histoire de la Paléoanthropologie. En: Dutour, O.; Hublin, J.-J. et Vandermeersch, B. (eds.), Objets et Méthodes en Paléoanthropologie, Comité des travaux historiques et scientifiques, 21-50 y PELAYO, F. (2007), Controvèrsies científiques i repercussions socials de la Paleontología Humana, Mètode, n. 53, 30-36. 
de pensiones para ampliar estudios en laboratorios y centros de investigaciones europeos. Esta medida ayudó a incrementar los contactos y a establecer relaciones de trabajo con grupos de investigación extranjeros que trabajaban con las técnicas más novedosas en la resolución de los problemas científicos más actuales. Desde sus cargos en la JAE, Ignacio Bolívar (1850-1914), director del Museo de Ciencias Naturales desde 1901 hasta el final de la Guerra Civil española, impulsó el programa de financiación de becados a instituciones científicas extranjeras, para que a la vuelta abrieran líneas de trabajo en el marco de nuevos proyectos de investigación científica.

La introducción de modernos programas de trabajo permitió que las actividades realizadas por los biólogos españoles en los centros dependientes de la JAE, contribuyeron a establecer los fundamentos de la metodología de trabajo y las prácticas científicas en áreas como la zoología, la botánica y la biología experimental ${ }^{2}$. En este marco se establecieron relaciones especialistas europeos en Evolución, Paleontología del Cuaternario y Prehistoria, lo que permitió la difusión de los nuevos descubrimientos paleoantropológicos y de las ideas más actuales con relación a la evolución humana.

Así, en el caso de la Biología, para adiestrarse en las prácticas de trabajo e investigación teórica en el marco del evolucionismo, José Gogorza (18591926), Eduardo Boscá (1843-1924), Antonio de Zulueta (1885-1971) y Margarita Comas (1897-1972), durante el período de su aprendizaje como pensionados siguieron estudios de evolución en el Laboratoire d'Evolution des êtres organisés de París, que dirigía Maurice Caullery (1868-1958).

Gogorza, en la memoria que redactó para la JAE, comentó su asistencia a los cursos orales, trabajos prácticos y de laboratorio impartidos por Caullery, Charles Pérez (1873-1952), Émile Guyenot (1885-1963) y Etienne Rabaud (1868-1956) ${ }^{3}$. Por su parte, Comas, tras su regreso a España, publicó algunos de sus trabajos experimentales en París, informó de la reunión sobre evolución organizada en París por el Centre Internationale de Synthèse, en la que

2 Gomis, A., Josa, J., Pelayo, F. y Fernández, J. (1988), Análisis de las publicaciones de ciencias biológicas de la JAE. En: SÁNCHEZ RON, J.M. (coord.), 1907-1987. La Junta para Ampliación de Estudios e Investigaciones Científicas. 80 años después, Madrid, CSIC, vol. II, pp. 381-399; COMPTE SART, A. (1988), La JAE y la investigación zoológica en España, Ibidem, pp. 429-464; GonZÁlez BuENO y GALlARDO, T. (1988), Los estudios botánicos en la JAE, Ibidem, pp. 465-484 y BARATAS DÍAZ, A. (1997), Introducción y desarrollo de la biología experimental en España entre 1868 y 1936, Madrid, CSIC.

3 Gogorza GonzÁlez, J. (1911), Estudios de Anatomía Comparada y de Embriología, Anales de la Junta para Ampliación de Estudios, 5, Memoria 6, Madrid, 249-293. 
participaron Guyenot y Caullery, y reseñó el libro de éste último, Le problème de l'Évolution (1931) 4 .

Por su parte Boscá, catedrático de Historia Natural en la Universidad de Valencia, fue pensionado por R.O. 21 de julio de 1909, con el objeto de estudiar la «Osteología de los grandes mamíferos y especies extintas», en museos de Historia Natural europeos, entre diciembre de 1909 y marzo de 1919, y argentinos, entre octubre de 1910 y enero de 1911. En París, entró en contacto con Marcellin Boule, a quien conoció en la galería de Anatomía del Jardín des Plantes, y con M. Caullery, de quien comentó que su laboratorio de Embriología era un centro de investigaciones sobre el evolucionismo desde el punto de vista lamarckista, centrado en el estudio de la influencia del medio sobre los organismos. Boscá asistió en la Sorbona a una conferencia de Caullery en la que éste disertó sobre los resultados obtenidos con relación a la evolución desde la perspectiva de la paleontología y la embriología. En Londres, Boscá contactó con A. Smith Woodward, vicedirector del British $\mathrm{Mu}$ seum of Natural History, quien había visitado un par de veces Valencia para ver la colección paleontológica Rodrigo Botet. En Haarlem, le recibió Eugene Dubois (1858-1940), descubridor del Pithecanthropus erectus en Java, que era profesor de la Universidad de Ámsterdam y director del Museo Teyler ${ }^{5}$.

Durante su viaje de estudios por los museos de historia natural de Buenos Aires y La Plata, Boscá conoció al paleontólogo Florentino Ameghino (18541911). Este, apoyándose en el hallazgo de fósiles humanos en la formación geológica pampeana que consideraba terciaria, mantuvo una explicación transformista según la cual la cuna de los precursores homínidos y de un supuesto «hombre terciario» había sido la Patagonia.

Con relación a líneas de investigación enfocadas hacia la evolución humana, hay que citar la que desarrollaron Manuel Antón Ferrándiz (1849-1929), director del Museo de Antropología, y sus discípulos Telesfóro de Aranzadi Unamuno (1860-1945) y Luis de Hoyos Sainz (1868-1951). Antón fue delegado y representante de la JAE en varios congresos internacionales de Antropología y Arqueología Prehistórica. Aranzadi, que fue colaborador de la Sección de Antropología del Museo de Ciencias Naturales, estuvo pensionado y siguió estudios de Etnología y Prehistoria en París y Berlín durante 1909. Fue

4 Comas, M. (1930), Conferencias y Reseñas Científicas de la Real Sociedad Española de Historia Natural, V, 1930, 37-38 y VII, 1932, 154-156.

5 Boscá Casanoves, E. (1911), Los Museos de París, Londres, Ámsterdam y Bruselas (Primera parte). Su visita durante los meses de enero a marzo de 1910, Anales de la Junta para Ampliación de Estudios e Investigaciones Científicas, 4 (1), pp. 1-61. 
delegado de la JAE en el Congrés Préhistorique de France de 1914. Por su parte, Hoyos Sainz, entre 1911 y 1913 amplió estudios de Antropología, becado por la JAE, en el Muséum National d'Histoire Naturelle de París y en el Völkerskunde Museum de Berlín

En 1911 y 1912, fue pensionado por la JAE Eduardo Hernández Pacheco (1872-1965), catedrático de Geología de la Universidad Central. Se instruyó en la organización de laboratorios de geología de diversas instituciones científicas europeas, adiestrándose en los métodos de trabajo de disciplinas como la paleozoología del Terciario y Cuaternario y la paleoantropología. En Francia visitó el Musée de Saint-Germain en Laye, que conservaba una rica colección de Prehistoria y estuvo en Paris, en el Museo de Historia Natural y en el Institut de Paléontologie Humaine, formándose con M. Boule y Armand Thevenin (1870-1918) en el estudio de la industria lítica y la fauna fósil cuaternaria; en Bruselas se documentó con el conservador del Musée Royale d'Histoire Naturelle Aimé-Louis Rutot (1847-1933), acerca del estado en que se encontraban las investigaciones encaminadas a determinar la existencia del hombre terciario y la cuestión de los eolitos, supuesta industria lítica terciaria. Por último, Hernández Pacheco pasó a la Universidad de Lyon, donde amplió sus conocimientos de mamíferos miocenos bajo la dirección de Charles Depéret (1854-1929).

A su vuelta a España, y con la experiencia adquirida en su viaje de ampliación de estudios y establecer contactos científicos con equipos de investigación especializados en Paleontología Humana y Prehistoria, Hernández Pacheco presentó un proyecto para crear un organismo científico que impulsara las investigaciones paleontológicas y prehistóricas. Su propuesta fue apoyada y, bajo la dependencia de la JAE, se creó, por RR.OO. de 28 de mayo de 1912 y 26 de mayo de 1913, la Comisión de Investigaciones Paleontológicas y Prehistóricas (CIPP), que quedó integrada en el Instituto Nacional de Ciencias Físico-Naturales, posteriormente Instituto Nacional de Ciencias, organismo al que pertenecía el Museo Nacional de Ciencias Naturales, el Jardín Botánico, el Laboratorio de Investigaciones Biológicas dirigido por S. Ramón y Cajal y el Museo de Antropología 6 .

El establecimiento de la CIPP tuvo lugar en un contexto muy sensibilizado con los hallazgos y protección del patrimonio prehistórico y arqueológico español, ya que un año antes se había promulgado la Ley que regulaba las excavaciones artísticas y científicas. Así, en el Artículo Primero de su Regla-

6 Véase SÁNCHEZ Ron, J.M. (coordinador) (1988), 1907-1987. La Junta para Ampliación de Estudios e Investigaciones Científicas. 80 años después, Madrid, CSIC, vol. I. 
mento (Real Decreto 1 de Marzo de 1912) se sometía a los preceptos de la Ley a «las excavaciones que se hicieran en busca de restos paleontológicos, siempre que en ellas se descubrieran objetos correspondientes a la Arqueología y a la Paleontología Antropológica».

La creación de la CIPP se justificó apelando al necesario apoyo del Estado a las investigaciones y exploraciones geológicas y paleontológicas de simas, cavernas y abrigos naturales. La CIPP quedaba encargada de organizar las investigaciones y estudios espeleológicos relacionados con las Ciencias Naturales y la Arqueología. Se establecía que su ubicación fuese el Museo de Ciencias Naturales de Madrid, donde se conservarían las colecciones que reuniera, y que funcionara en las mismas condiciones que el resto de entidades pertenecientes al Instituto Nacional de Ciencias. El marqués de Cerralbo (1845-1922) fue nombrado director de la CIPP. Otros cargos designados fueron los de Hernández Pacheco como jefe de trabajos, Juan Cabré Aguiló (1882-1947), como Comisario y el conde de la Vega del Sella (1870-1941), colaborador. Más adelante se integraron Hugo Obermaier, Paul Wernet (1889-1972), Ismael del Pan (1889-1968) y Orestes Cendrero (1887-1946).

Inició entonces Hernández Pacheco un programa de investigación centrado en el estudio de las faunas fósiles de España, especialmente de mamíferos terciarios y cuaternarios, y en Prehistoria y Paleoantropología. Los resultados de la actividad investigadora de la CIPP, que se recogen en las memorias bianuales publicadas por la JAE, fueron en gran medida difundidas a través de la publicación de la «Serie Geológica de los Trabajos del Museo», de la que se editaron treinta y nueve monografías entre 1912 y 1935 . Un resumen de la labor realizada en estas líneas de trabajo durante los primeros años se conoce a través de la intervención de Hernández Pacheco en el Congreso de la Asociación Española para el Progreso de las Ciencias, celebrado en Valladolid en 1915. Allí impartió una conferencia en la que expuso el estado actual en que se encontraban en ese momento en España, las investigaciones relacionadas con la Paleontología y la Prehistoria ${ }^{7}$.

Al mismo tiempo, y como las bases generales por las que, según la JAE, había de regirse el Museo de Ciencias Naturales contemplaba la organización de trabajos de investigación en laboratorios y cursos de ampliación, dirigidos por profesores designados por la JAE, Hernández Pacheco dirigió y organizó los laboratorios de geología y el seminario investigaciones geológicas y pa-

7 Hernández Pacheco, E. (1915), Estado actual de las investigaciones en España respecto a Paleontología y Prehistoria, Asociación Española para el Progreso de las Ciencias, Quinto Congreso celebrado en Valladolid, I, pp. 117-176. 
leontológicas del Museo, una de cuyas líneas de investigación se enfocó hacia el estudio de la Paleoantopología ${ }^{8}$. En los laboratorios de paleontología del Museo, Hernández Pacheco formó a un grupo de doctores en Ciencias Naturales, con los que constituyó un destacado equipo de investigación. Algunos de ellos fueron pensionados para trabajar y establecer redes de investigación con grupos de paleontólogos de Francia y Alemania, con los que se mantenían contactos científicos. Además de adoptar del grupo del laboratorio de paleontología de la Universidad de Lyon, encabezado por Depéret, su orientación paleontológica dirigida a reconstruir series filéticas y a establecer rutas de migraciones, se establecieron relaciones científicas con otros equipos de investigación europeos. Así, Juan Dantín Cereceda (1881-1945) y José Royo Gómez (1895-1961) estuvieron trabajando en la Universidad de Lyon, junto con Depéret y Fréderic Roman (1871-1943); Bartolomé Darder Pericás (1894-1944) realizó una estancia científica en París, en la Sorbona y en la Societé Géologique de France, formándose con Gustave Dollfus (18501931), M. Boule y Louis Gentil (1868-1925); por último, Federico Gómez Llueca (1859-1960), también trabajó en Lyon con Depéret, en Munich con Max Schlosser (1854-1933) y con Ferdinand Broili (1874-1946) y en París también con Boule.

En el grupo de investigación del Museo de Ciencias Naturales que contribuyó a la consolidación de una paleontología evolucionista, se encontraron naturalistas que se encargaron del estudio y conservación de importantes colecciones paleontológicas, como Ángel Cabrera (1879-1960) $)^{9}$, que pasó en 1925 a la Argentina como Jefe del Departamento de Paleontología del Museo de La Plata, y Royo Gómez, Jefe de la Sección de Paleontología del Museo ${ }^{10}$.

Royo estuvo como pensionado por la JAE en 1927 en Inglaterra, recorriendo el condado de Sussex para estudiar la facies weáldica y conocer el

8 Pelayo, F. (1998), La Real Sociedad Española de Historia Natural y la consolidación de la Geología, la Paleontología y la Prehistoria en España (1900-1936). En: A. Baratas y J. Fernández (Eds.) Aproximación histórica a la Real Sociedad Española de Historia Natural, Memorias de la Real Sociedad Española de Historia Natural, Tomo I, Segunda época, 251-258.

9 Biraben, M. (1960), Angel Cabrera 1879-1960, Neotropica, vol. 6, n. 20, 33-37. Con relación a sus ideas evolucionistas véase: CABRERA, A. (1926), Evolución, variación y herencia, Rosario, Asociación Cultural de Conferencias de Rosario.

10 Sos Baynat, V. (1962), José Royo Gómez (1895-1961), Boletín de la Real Sociedad de Historia Natural (G), 60, 151-175; GLICK, T. (1995), Josep Royo Gómez. Castelló de la Plana, 1885 - Caracas, 1961, Ciència, Tècnica als Països Catalans: una aproximació biogràfica, Barcelona, Fundació Catalana per a la Recerca, II, 1277-1304. 
yacimiento de Piltdown ${ }^{11}$. Divulgó el evolucionismo dictando cursos y conferencias, como la impartida en la Universidad Central en 1927 con el título de «La paleontología y la evolución de las especies» ${ }^{12}$. En este trabajo Royo comentó que la evolución de los primates y del hombre era un problema muy debatido, al tratarse de nuestros ancestros. Exponía que los restos fósiles humanos pertenecientes al Cuaternario de Europa eran humanos de diferentes especies, a pesar de que algunos mostraban caracteres que les aproximaban a los monos antropomorfos. En cambio, el Pithecanthropus de Java era considerado como un antropomorfo de evolución avanzada que constituía una rama paralela a la de los humanos, sin ninguna relación con ella. Según Royo, en ese momento, finales de los años veinte, había dos tendencias para explicar el origen de la Humanidad. Una de ellas consideraba que los ancestros de los humanos había que buscarlos en los monos antropoides del Terciario medio, como Dryopithecus y Sivapithecus. La otra orientación defendida por Osborn, defendía que los humanos constituían una familia distinta y separada del resto de los primates. En artículo posterior, «La lentitud de la evolución en las faunas continentales de mamíferos» (1928), Royo discutió sobre los ritmos y modalidades de la evolución de las especies, tanto en las velocidades de la transformación, como en el sentido de la variación con relación al tamaño.

Entre las contribuciones del grupo de Paleontología del Museo destacaron los trabajos sobre cuestiones paleoantropológicas y los que abordaron el estudio de problemas evolutivos, filogenéticos, ontogénicos y biogeográficos, incidiendo en las relaciones paleobiogeográficas, a través de puentes intercontinentales, entre las faunas terciarias y cuaternarias de Norteamérica, Europa y Africa ${ }^{13}$.

En cuanto a las orientaciones teóricas seguidas por los paleontólogos españoles, puede hablarse de un cierto eclecticismo. En primer lugar hay que referirse al interés por las ideas sobre el origen del hombre terciario del paleontólogo argentino Ameghino, que mostraron tanto Hernández Pacheco,

11 Montero, A. (1996), J. Royo Gómez y sus viajes europeos pensionado por la Junta para Ampliación de Estudios, Geogaceta, 19, 183-184.

12 Royo Gómez, J. (1927), «La paleontología y la evolución de las especies», Conferencias y Reseñas Científicas de la Real Sociedad Española de Historia Natural, 2, 189-205.

13 HeRnÁNDEZ PACHECO, E. (1913-1914), Un grupo nuevo de Cervicornios miocenos, Revista de la Real Academia de Ciencias Exactas, Físicas y Naturales, XII, 570-608; PAN, I. DEL (1919), Paleografia de los mamíferos cuaternarios de Europa y Norte de África, Madrid, Trabajos del Museo de Ciencias Naturales; HeRnÁndez PACHECO, E. (1921), La llanura manchega y sus mamíferos fósiles, Madrid, Trabajos del Museo de Ciencias Naturales y RoYo GóMEZ, J. (1922), El mioceno continental, Madrid, Trabajos del Museo de Ciencias Naturales. 
Obermaier y Manuel Antón en Madrid como Boscá en Valencia. Según Ameghino, desde la Patagonia el género humano se había expandido hacia el resto del mundo. El género Homo había aparecido en el Plioceno de Patagonia, siendo el Homo Pampaeus o Prothomo la primera forma genérica humana que había aparecido en la Tierra. Una rama de los monos de Patagonia había evolucionado y marchado hacia la humanización, pasando por las etapas o tipos intermedios entre el mono y el hombre: Tetraprothomo, Triprothomo, Diprothomo y Prothomo. El Prothomo u Homo pampaeus, había evolucionado en la Patagonia hacia formas del hombre terciario. Por el antiguo puente terrestre guayano-senegalense, una línea de antecesores había pasado a África a principios del Plioceno, desprendiéndose una rama que originó el Homo afer, o primitivas poblaciones negras y australianas. De otra línea se había desprendido la cepa que había originado el Homo sapiens. Había sido el resultado de la evolución del Homo pampaeus en Sudamérica, que había emigrado por el istmo de Panamá hacia América del Norte, desde donde se había expandido, dividiéndose en dos grupos, uno por el estrecho de Bering hacia el continente asiático, y otro a Europa, por el puente que unía Canadá con el continente europeo a fines del Plioceno y principios del Cuaternario. Un grupo se había aislado, degenerando en el Homo primigenius u hombre de Neandertal, de Spy y de la Chapelle-aux-Saints, y los demás se difundieron por Europa. En este esquema de Ameghino, el antecesor del hipotético Homosimius del Plioceno europeo postulado por el prehistoriador francés Gabriel de Mortillet había sido el Tetraprothomo del Mioceno de la Argentina. Por su parte, el Triprothomo era el ancestro del Pithecanthropus, que, según Ameghino, no era un precursor del hombre sino una rama lateral divergente, que había desaparecido no por transformación sino por extinción ${ }^{14}$.

Lo peculiar de esta ambiciosa explicación de Ameghino acerca del origen y expansión de la Humanidad llevó a Hernández Pacheco a difundir en 1910 el pensamiento del paleontólogo argentino, a través de un artículo publicado en el Boletín de la Institución Libre de Enseñanza ${ }^{15}$, y de una comunicación remitida a la Real Sociedad Española de Historia Natural ${ }^{16}$.

14 Ameghino, F. (1907), Notas preliminares sobre el Tetraprothomo argentinus: un precursor del Hombre del mioceno superior de Monte Hermoso, Anales del Museo Nacional de Historia Natural de Buenos Aires, IX, 105-242.

15 HeRnÁndez PACHECO, E. (1910), Los ancestrales terciarios del hombre según las investigaciones del Dr. Ameghino, Boletín de la Institución Libre de Enseñanza, n. 607, 306-313.

16 Hernández Pacheco, E. (1910), El Diprothomo platensis. Un precursor del hombre plioceno inferior de Bueno Aires, Boletín de la Real Sociedad Española de Historia Natural, $\mathrm{X}, 311-316$. 
Por su parte, Boscá, siguió la orientación de Ameghino a la hora de determinar el esqueleto fósil del «hombre de Samborombón», perteneciente a la colección paleontológica Rodrigo Botet, formada por ejemplares sudamericanos y conservada en Valencia ${ }^{17}$. Boscá consideró que estos restos fósiles humanos perteneciente a una raza humana sudamericana desaparecida eran de edad geológica terciaria, lo que dio lugar a una polémica, al criticar Faustino Barberá, presidente del Instituto Médico Valenciano, la datación geológica y carácter primitivo que se habían atribuido a dichos restos fósiles ${ }^{18}$. Posteriormente, el jesuita Jaime Balasch, profesor de Historia Natural del Colegio San José de Valencia, criticó a Boscá y Ameghino y apoyó las tesis de Barberá acerca de su edad cuaternaria y contrarias a considerar a los restos fósiles de Samborombón como un hipotético ejemplar de «hombre terciario» ${ }^{19}$.

Posteriores y más sólidas fueron las influencias francesas y alemanas, concretadas en referencias a autores como Karl von Zittel (1839-1904) y Depéret, se asumieron tendencias neolamarckistas y saltacionistas, tradición que en España se remontaba al siglo pasado. Junto a estas corrientes tuvieron influencia orientaciones ortogenéticas procedentes de Estados Unidos, fundamentalmente a través de los trabajos de los paleontólogos del American Museum of Natural History Henry F. Osborn, William D. Matthews (1871-1930) y William K. Gregory y del profesor de la Universidad de Princeton William B. Scott (18581947 ${ }^{20}$, cuyo libro, La teoría de la evolución y las pruebas en que se funda (Madrid, Espasa Calpe, 1920) fue traducido por Antonio de Zulueta.

Papel destacado como divulgador de las ideas relacionadas con el origen de la Humanidad fue Vicente Sos y Baynat (1895-1992). Vinculado al Museo de Ciencias Naturales como preparador y profesor de Geología, fue nombrado por la JAE profesor del Instituto-Escuela de Madrid. En la publicación Confe-

17 Boscá Casanoves, E. (1910), El esqueleto humano fósil del arroyo de Samborombón (América del Sur), Asociación Española para el Progreso de las Ciencias, Congreso de Zaragoza, 4 (1 ${ }^{\text {a }}$ parte $), 221-235$.

18 BARBERÁ, F. (1907), Nota relativa al esqueleto humano de la colección paleontológica Botet en Valencia, Revista Valenciana de Ciencias Médicas, 9, 305-313.

19 Véase CAtalá Gorgues, J. I. (2004), El desarrollo de una carrera científica en un contexto institucional precario: el caso del naturalista Eduardo Boscá y Casanoves (18431924), Cronos, vol. 7, n. 1, 3-60.

20 El estado de las relaciones entre paleontología y evolución en las primeras décadas del siglo XX puede consultarse en Bowler, P.J. (1983), The Eclipse of Darwinism. AntiDarwinian Evolution Theories in the Decades around 1900, Baltimore-London, John Hopkins University Press y PINNA, G. (1995), La natura paleontologica dell'evoluzione, Torino, Giulio Einardi Editore. 
rencias y Reseñas Científicas editada por la Real Sociedad Española de Historia Natural, Sos contribuyó a la divulgación científica, reseñando dos artículos de paleontólogos franceses, Henri Vallois (1889-1981), que sería director del Institut de Paléontologie Humaine entre 1942 y 1971, y Jean Piveteau (1899-1991), en los que se exponían las opiniones de los especialistas en el debate sobre los orígenes de la Humanidad ${ }^{21}$.

En el primero de estos trabajos, Sos tradujo y comentó el trabajo de Vallois en el que éste discutía y comparaba las teorías modernas sobre el origen múltiple del hombre, polifiléticas, con la clásica explicación monofilética. La mayor parte de los árboles genealógicos diseñados por autores como Dubois, Elliot Smith, Keith, Gregory, etc., se basaban todos en una concepción monofilética, diferenciándose sus opiniones en el punto del tronco común compartido con los primates en el que se había desgajado la rama o el phylum del grupo humano. Las tendencias polifiléticas se fundamentaban en la concepción de divergencia adaptativa, según la cual las diferencias de los grupos humanos eran las trazas del origen independiente de cada uno de ellos. El artículo de Vallois discutía las explicaciones polifiléticas de autores como Hermann Klaatsch (1836-1916), Giuseppe Sergi (1841-1936) y Gioacchino Sera (1878-1960). Vallois terminaba sugiriendo que con el estado actual del conocimiento paleontológico, podía haber compatibilidad entre las concepciones monofiléticas y polifiléticas. Pensaba que la familia Hominidae tenía un origen monofilético pero aceptaba que internamente las diversas ramas de esta familia podian desarrollarse siguiendo un modelo polifilético ${ }^{22}$.

En cuanto al trabajo de Piveteau difundido por Sos, se trataba de una conferencia impartida en el Institut de Paléontologie Humaine, en el que el paleontólogo francés discutía sobre los orígenes humanos, según los datos de que se disponían en ese momento. Partía de la brusca aparición de la Humanidad en el Cuaternario, tanto las formas antiguas representadas por los restos fósiles de Mauer, Piltdown y Neandertal, como los tipos Grimaldi, Cromagnon y Chancelade que definían el hombre moderno. Se refería a dos tendencias opuestas. Una de ellas relacionaba a los humanos con los antropoides, según una línea vinculada al Propliopithecus y Dryopithecus. La otra sostenía que el grupo humano se había desgajado del tronco común en una época muy

21 Sos Baynat, V. (1927), ¿Existen varios orígenes humanos?, Conferencias y Reseñas Cientificas, II, 161-163 e Ibidem, La paleontología y el origen del hombre, Conferencias y Reseñas Cientificas, II, 218-220.

22 VAllois, H. (1927), Y a-t-il plusieurs souches humaines?, Revue Genérale des Sciences pures et apliques, 38, 201-209. 
remota en el pasado, en el Eoceno, y a partir de ese momento su desarrollo continuó en una línea independiente y paralela a la del resto de las ramas de los primates. Pivetau terminaba decantándose por esta última orientación, que defendían entre otros su maestro Boule, ya que le parecía más conforme con las leyes generales de la evolución paleontológica 23 .

El Institut de PalÉontologie Humaine Y SU INFLUENCIA EN EL DESARROLLO DE LA PALEOANTROPOLOGÍA EN ESPAÑA

Particularmente intensas fueron las relaciones científicas establecidas desde el Museo de Ciencias Naturales de Madrid, con el Institut de Paléontologie Humaine (IPH), dirigido por M. Boule. La conexión con Boule fue determinante para afrontar desde el Museo un programa de investigación en Paleontología Humana. Un reconocimiento de la influencia que tuvo el IPH en el desarrollo de la Paleoantropología española fue expuesto en 1923 por Hernández Pacheco en una conferencia impartida en el Ateneo de Madrid, con el título «Los estudios de Paleontología Humana en España y el influjo en ellos del Príncipe Alberto I de Mónaco». En este trabajo el naturalista español explicó que tras ser nombrado catedrático de Geología de la Universidad Central, quiso seguir el rumbo marcado por Boule, Smith Woodward y Osborn, orientando su actividad científica hacia la Paleontología Humana, el problema más actual en esos momentos. Por eso había solicitado a la JAE una pensión para ampliar conocimiento en esta disciplina y había solicitado a su regreso la creación del CIPP, organismo científico cuyo objeto de estudio era la Paleoantropología ${ }^{24}$.

El Institut de Paléontologie Humaine había sido creado en 1910 bajo el mecenazgo del príncipe Alberto I de Mónaco, quien anteriormente había demostrado su interés científico patrocinando investigaciones oceanográficas y prehistóricas. En este sentido, el príncipe, financió las excavaciones paleoantropológicas del canónigo Villeneuve y Boule en las grutas de Grimaldi, donde se desenterraron restos fósiles humanos que se interpretaron como ancestros de tipos humanos centroafricanos.

La fundación del IPH en 1910 establecía que su objetivo era el estudio de todo lo relativo al hombre fósil y sus precursores inmediatos, hasta el final del

23 Piveteau, J. (1927), Les théories sur l'origine de l'Homme avant et aprés Darwin, L'Anthropologie, XXXVII, 355-380.

24 Hernández PACHeCO, E. (1923), Los estudios de Paleontología Humana en España y el influjo en ellos del Príncipe Alberto I de Mónaco, Madrid, p. 13. 
neolítico. Boule fue nombrado director y los clérigos Henri Breuil y Obermaier, profesores de Etnografía prehistórica y de Geología aplicada a la Prehistoria respectivamente. Desde un principio el IPH fue un proyecto controvertido. De principio, le afectó el debate entre ciencia y religión, siendo acusado, por un lado, de ser una institución laicista y por el otro, de haber detrás una operación clerical para dar cabida a incompetentes «prêtes-prehistoriens». Además, se le criticó la incorporación de un alemán, Obermaier, acto que fue considerado antifrancés, en un período de especial sensibilidad política y nacionalista, como eran los años anteriores a la Primera Guerra Mundial. Para terminar, el crónico déficit financiero y la lucha de influencias entre Boule y Breuil, fueron dos factores que contribuyeron negativamente en el desarrollo del IPH ${ }^{25}$.

Tras la visita de Alberto de Mónaco de las grutas prehistóricas de Santander, el IPH financió entre 1910 y 1914 excavaciones en la cueva del Castillo. Pero con el estallido del conflicto bélico se paralizaron las actividades científicas y Obermaier fue cesado en su cargo en el IPH debido a su nacionalidad alemana. $\mathrm{Al}$ año siguiente, el prehistoriador germano se vinculó al Museo de Ciencias Naturales de Madrid, incorporándose como profesor agregado al CIPP. En la colección de memorias publicadas por esta Comisión, se publicaron dos trabajos de Obermaier, uno en colaboración con Hernández Pacheco, dedicado al estudio de la mandíbula neandertaloide de Bañolas, y el segundo fue un amplio trabajo de síntesis del prehistoriador alemán sobre el hombre fósil.

A pesar de todo no fueron fáciles esos años para Obermaier, ya que fue acusado de antipatriota, desleal y francófilo por la comunidad alemana en España. Además, apenas estuvo cinco años vinculado al CIPP. En 1919 se le cesó en su puesto de la Comisión, a causa del deterioro de sus relaciones con el personal del Museo de Ciencias Naturales ${ }^{26}$.

Por último, la relación científica con el IPH permitió mantener la importante tradición paleontológica francesa en España, ya que Boule fue maestro de Camille Arambourg (1885-1969), Teilhard de Chardin (1881-1955) y Jean Piveteau, paleontólogos franceses que influirían años más tarde, durante las décadas de los años cuarenta y cincuenta, en sus colegas teilhardianos españoles.

25 Hurel, A. (2000-2001), La création de l'Institut de Paléontologie Humaine par le Prince Albert I de Monaco. Une étape vers l'institutionnalisation de la Préhistoire, Bulletin du Musée d'Anthropologie Préhistorique de Monaco, n. 41, 50-62.

26 Moure Romanillo, A. (1996), Hugo Obermaier, la institucionalización de las investigaciones y la integración de los estudios de Prehistoria en la Universidad española. En: El Hombre fósil 80 años después, Santander, Universidad de Cantabria, Fundación Marcelino Botín, 17-50. 
LA Difusión DE LA PALEOANTROPOLOGÍA EN ESPAÑA DURANTE EL PRIMER TERCIO DEL SIGLO XX

El primer trabajo español del siglo XX que comunicó los hallazgos más recientes de restos fósiles humanos fue un artículo de T. de Aranzadi publicado en 1909 en el Boletín de la Sociedad Española de Historia Natural. En él Aranzadi reseñó tres descubrimientos: la mandíbula de Mauer en Heidelberg, el esqueleto excavado en Le Moustier, Dordogne, por Otto Hauser y los restos humanos desenterrados en La Capelle-aux-Saints.

Aranzadi realizó una completa descripción de la mandíbula humana fósil hallada en 1907 y estudiada por Otto Schoetensack (1850-1912). Comentó en su artículo que, aunque tenía rasgos antropoides debido a su aspecto macizo y grueso, los dientes eran completamente humanos, con molares semejantes a los de los aborígenes australianos y una cementación y espesor dental parecido a los de los europeos. A partir de estos datos, junto al pequeño tamaño de los dientes, Schoetensack pensaba que la mandíbula debía haber pertenecido a un antecesor, próximo al punto de partida de la evolución hacia antropoides y hacia los tipos humanos negros y blancos. Aranzadi, en cambio, creía que los caracteres pre-antropoides debían ser resultado de atavismo y que por comparación con la mandíbula de Spy, al resto fósil de Mauer se le podía calificar de pre-neandertaloide.

El segundo descubrimiento que presentaba en su artículo Aranzadi fue el polémico hallazgo de Le Moustier, realizado por Hauser en unos terrenos que había comprado en el valle de la Vézère. La excavación provocó el rechazo de los prehistoriadores franceses, ya que Hauser no contó con ellos, recurriendo a Klaatsch y desenterrando el esqueleto en presencia también de otros antropólogos alemanes. El trabajo de reconstrucción del cráneo realizado por Klaatsch, en los que describió caracteres neandertaloides, fue criticado por Boule. En paralelo, los autores alemanes criticaron a los franceses por no dar publicidad a sus hallazgos prehistóricos.

Por último, Aranzadi hacía referencia al descubrimiento del esqueleto neandertal en La Chapelle-aux-Saints por los sacerdotes franceses A. y J. Bouyssonie y L. Bardon, que fue remitido al museo de Historia Natural de París que ser estudiado por Boule. Por de pronto, comentaba Aranzadi, los alemanes criticaron la labor de los sacerdotes franceses en el yacimiento, acusándoles de ser meros aficionados a la Prehistoria y no haber sido cuidadosos en las tareas de excavación. Este ejemplar se encontró en mejor estado de conservación que el hallado en Le Moustier y presentaba las características del tipo neandertal perfectamente marcadas. Boule, estudiando el cráneo, le 
atribuyó una inteligencia casi nula, pesar de su gran capacidad craneal, y morfológicamente le situó en una posición intermedia entre el Pithecanthropus de Java y las razas humanas actuales más inferiores.

Del resto del esqueleto, comentaba Aranzadi, no se tenía un conocimiento completo, por lo que no cabía justificar las tesis de los paleontólogos belgas Julien Fraipont (1857-1910) y Max Lohest (1857-1926), recogidas en artículos de vulgarización, que el tipo humano de Spy (Bélgica), identificado como neandertal, se caracterizaba por su marcha inclinada y a veces casi a gatas. Con relación al color de la piel y la pilosidad del hombre de La Chapelle-auxSaints, decía Aranzadi que todo lo que se había escrito y dibujado en las revistas de vulgarización era pura fantasía. Además, como periódicos franceses y alemanes habían publicado la imagen de Boule con un cráneo de gorila en la mano, muchos profanos habían creído que era el cráneo encontrado en La Chapelle-aux-Saints.

Aranzadi terminaba comentando que el ejemplar fósil de La Chapelle-auxSaints no hacía considerar al tipo neandertal más pitecoide que lo que se había considerado hasta entonces, aunque sí confirmaba varios caracteres que antes se consideraban dudosos o simples conjeturas. Tampoco ayudaba a resolver la polémica entre Gustav Schwalbe (1844-1916) y Kazimir Stolyhwo (1880-1966) acerca de la discontinuidad entre Homo primigenius o de Neandertal y Homo sapiens. De hecho, decía Aranzadi, el neandertal era muy distinto del tipo negroide hallado en las grutas de Grimaldi, casi contemporáneo del hombre de La Chapelle. Además, la industria de éste último era más primitiva que la de Grimaldi y que la de Cromagnon, cuyos caracteres anatómicos también eran muy diferentes. De manera que el hallazgo de La Chapelleaux-Saints no resolvía el problema de si había que considerar al neandertal el antecesor más antiguo de las razas europeas modernas dolicocéfalas o era el representante de otro pueblo distinto ${ }^{27}$.

Durante el período comprendido entre 1914 y 1918, años en que gran parte de Europa estuvo afectada por la Primera Guerra Mundial, se publicaron en España una serie de trabajos que exponían el estado de la cuestión sobre los orígenes de la Humanidad. Algunos recogieron las novedades de forma indirecta, al tratar otras cuestiones. Así, tras el hallazgo de restos del antropoide fósil Dryopithecus en Cataluña, Luis Mariano Vidal (1842-1922) envió un molde de la mandíbula a Smith Woodward. Este comparó el ejemplar fósil con las mandíbulas de varios primates y con las de Homo heidelbergensis y

27 Aranzadi, T. (1909), Los últimos descubrimientos del hombre fósil en Europa, Boletín de la Sociedad Española de Historia Natural, IX, 316-324. 
del Eoanthropus dawsoni, que acababa de ser hallado en Piltdown ${ }^{28}$. Vidal se hizo eco del trabajo de Woodward y comunicó en la sesión de Barcelona de la Sociedad Española de Historia Natural, celebrada el 23 de mayo de 1914, que del estudio comparativo se desprendía la sínfisis mandibular del Dryopithecus era intermedia entre la del Mesopithecus y la del Homo heidelbergensis de Mauer y podía ser una forma común a partir de la cual habían divergido en dos direcciones, por un lado los monos antropoides y los humanos por el otro ${ }^{29}$.

No faltaron en estos años trabajos críticos con las propuestas evolucionistas para explicar el origen del hombre. Este fue el caso de los publicados por el jesuita Jaume Pujiula (1869-1958), biólogo formado en Alemania, director del Laboratorio de Biología del Ebro, más tarde Instituto Biológico de Sarriá (Barcelona). La revista Ibérica: el progreso de las ciencias y de sus aplicaciones, que comenzó a publicarse en 1914, fue un vehículo de expresión en el que los jesuitas y su entorno pudieron divulgar su doctrina, basada en la defensa de los valores católicos, el rechazo de las formulaciones materialistas y la armonía entre ciencia y religión ${ }^{30}$.

Los primeros artículos de Pujiula en 1914 fueron para dar noticia de los hallazgos de fósiles humanos en Obercassel (Alemania) y en África, en la colonia alemana de Oldoway (actual Olduvai, Tanzania). En éste último criticaba a Hans Reck (1866-1937), quien había descubierto un esqueleto africano al que en principio se le atribuyó una edad de ciento cincuenta mil años, por sostener que durante el período diluvial al lado de hombres de aspecto casi de animal, existían pueblos muy desarrollados. Apoyándose en la obra Der Mensch 1886, $3^{\mathrm{a}}$ edición 1912) del profesor de Munich Johannes Ranke (1836-1916) y en otros anatomistas y antropólogos alemanes, como Julius Kollmann (1834-1918) y Gustav Frtisch (1838-1927), Pujiula sostenía que el hombre no había sufrido ninguna modificación física desde su aparición en la Tierra, lo que concordaba con el relato bíblico de la creación. Según Fritsch, el esqueleto de Olduvai era semejante a los hallados en Grimaldi. En éstos se habían observado caracteres «negroides», por lo que se había establecido que

28 Smith Woodward, A. (1914), On the Lower Jaw of an Anthropoid Ape (Dryopithecus) from the Upper Miocene of Lérida (Spain), Quarterly Journal of the Geological Society of London, vol. 70, 316-320.

29 VIDAL, L. M. (1914), Resumen de la nota de A. Smith Woodward sobre el Dryopithecus de Seo de Urgel, Boletín de la Real Sociedad Española de Historia Natural, XIV, 288-289.

30 Pujiula, J. (1914), El hombre diluvial de Olduway, Ibérica, I, 379-381; Ibidem (1914), Dos esqueletos diluviales descubiertos en Obercassel (Alemania), Ibérica, II, págs. 22-223; Ibidem (1915), El mono de transición o el Pithecanthropus erectus de Dubois, Ibéri$c a$, III, 110-112; Ibidem (1916), Otra vez el hombre prehistórico, Ibérica, V, 90-93. 
la raza Grimaldi estaba relacionada con las actuales poblaciones centroafricanas. Pujiula recomendaba prudencia con los descubrimientos de hombres primitivos, ya que los datos de que se disponían de los tipos diluviales europeos no eran seguros. Ponía como ejemplo el caso de la raza de Neandertal, cuyo ejemplar tipo carecía de una datación fiable. Además, tachaba de fantasía a las representaciones de los neandertales como seres que marchaban inclinados o con el cuerpo encorvado, imagen que se había colado incluso en algún texto de enseñanza secundaria ${ }^{31}$.

En 1915, y dentro de la serie de monografías editadas por el Museo de Ciencias Naturales pertenecientes a los trabajos financiados por la JAE y realizados en la CIPP, Obermaier y Hernández Pacheco publicaron su estudio sobre la mandíbula neandertaloide de Bañolas ${ }^{32}$. Para ellos, este fósil presentaba rasgos morfológicos que le diferenciaban de los tipos Cromagnon y Grimaldi. Lo consideraban neandertal con un grado de evolución mayor que el de otros restos óseos del mismo tipo, como el de La Chapelle-aux-Saints. En la bibliografía utilizada remitían a Klaatsch y a Boule, además de la revisión crítica que había hecho Gustav Schwalbe (1844-1916) del trabajo del paleontólogo francés sobre el neandertal de La Chapelle. Entre los autores que reseñaron este trabajo se encontró el propio Boule. En su revista, L'Anthropologie, dudó que el resto fósil de Bañolas fuese neandertal, ya que los caracteres diferenciales progresivos citados por los autores tenían más valor taxonómico que los comunes a dicho tipo, que eran de menor importancia ${ }^{33}$.

Ese mismo año de 1915, y con otra índole, propia de la divulgación científica, se publicó en la revista cultural fundada Por esos Mundos, una referencia al hombre de Piltdown. Se comentaba el descubrimiento en una cantera de las riberas del Tajo, cerca de Trillo (Guadalajara) de un fémur humano fósil. El autor del artículo, Antonio Pareja Serrada, citaba que antes de empezar la gran guerra en Europa el mundo científico debatía acerca de los huesos fósiles hallados en Piltdown (Sussex, Inglaterra). Eran diferentes por su aspecto y dimensiones de los estudiados hasta entonces. El trozo de mandíbula inferior

31 Pujiula (1914), págs. 379-381.

32 Hernández Pacheco, E. y Obermaier, H. (1915), La mandibula neandertaloide de Bañolas, Madrid, Museo Nacional de Ciencias Naturales.

33 Una historia de la mandíbula fósil de Bañolas y de su interpretación por los especialistas puede verse en: MARoto, J. y SOlER, N. (1993), Antecedents, i problemàtica de l'estudi de la mandíbula de Banyoles. En: J. Maroto (Ed.), La mandibula de Banyoles en el context dels fòssils humans del Pleistocè, Girona, Centre d'Investigations Arqueologique de Girona, pp. 36-54. 
sin dientes, tenía una configuración extraña y grandes dimensiones. La polémica se establecía al debatirse si era restos humanos o de algún antropoide. La singularidad del artículo es que reproduce en sus páginas una supuesta representación del «Hombre de Piltdown», en la que aparece un tipo humano peludo, encorvado y con un largo palo en la mano derecha ${ }^{34}$.

Los dos trabajos anteriormente citados fueron objeto de revisión crítica por parte de Pujiula, desde las páginas de la revista Ibérica. En su artículo «Otra vez el hombre prehistórico» (1916), el jesuita comentaba la interpretación de la mandíbula fósil de Bañolas que había realizado Hernández Pacheco en el Congreso de Valladolid de la Asociación Española para el Progreso de las Ciencias. En su línea de pensamiento creacionista, intentaba matizar que el tipo neandertal no era una especie diferente, sino que había que considerarlo como una subespecie o una raza. Más crítico fue con el artículo de Pareja Serrano. En concreto de la reconstrucción del hombre de Piltdown decía que la figura era tendenciosa hasta la pared de enfrente.

Más importante fue la publicación de la obra El hombre fósil (1916) de Obermaier, que fue financiada por la JAE, en el marco de los trabajos del CIPP y de la que se publicaría una segunda edición ampliada en 1925. Ese mismo año sería traducida al inglés, editada por The Hispanic Society of America y con una introducción de H. F. Osborn. Este había realizado un viaje por España y había coincidido con Obermaier durante los trabajos de excavación en Puente Viesgo (Cantabria).

En el prólogo, el prehistoriador alemán mostraba su agradecimiento al director del Museo de Ciencias Naturales, Bolívar, a los responsables de la CIPP, Hernández Pacheco, conde de la Vega del Sella y marqués de Cerralbo, y a M. Antón, director del Museo de Antropología. También reconocía la importancia del patrocinio de la JAE y de la labor de Paul Wernert e Ismael del Pan, agregados al laboratorio de Geología del Museo, que habían sido los traductores del alemán al español. Obermaier justificaba su libro, un tratado didáctico en forma de manual que contenía todo lo concerniente al hombre fósil, debido al gran desarrollo que había alcanzado la Paleontología Humana y sus disciplinas auxiliares.

En su obra Obermaier discutía en un primer capitulo que de veinte páginas la polémica que existía desde el siglo XIX entre prehistoriadores acerca de la posible existencia del «hombre terciario» y de la industria eolítica. El siempre se mostró contrario a considerar a los eolitos herramientas humanas de edad

34 Pareja Serrano, A. (1915), De la Prehistoria Española. El hallazgo arqueológico de Trillo, Por esos Mundos, Octubre, 397-399. 
terciaria, defendiendo que eran piedras de origen natural cuyas formas se asemejaban a los artefactos hechos por hombres primitivos. Más importante era capítulo noveno dedicado a la Paleoantropología, que ocupaba las páginas 265 a 311, que incluían las seis últimas páginas de una completa bibliografía actualizada. En este capítulo Obermaier seleccionaba y compilaba todo el material óseo humano fósil del Cuaternario conocido en ese momento, agrupados primero desde un punto de vista geográfico. Eliminaba los falsos fósiles humanos, como la desacreditada mandíbula de Moulin-Quignon y citaba el hallazgo reciente de los restos de Piltdown. El se adhería a la opinión de Smith Woodward, Elliot Smith, Keith y Osborn, entre otros, que consideraban que el cráneo y la mandíbula del Eoanthropus dawsoni pertenecían al mismo individuo.

Posteriormente Obermaier integraba los datos agrupándolos según tipos fósiles temporales e incluía en el Paleolítico Superior las razas de Cromagnon, Grimaldi y Predmost y en el Inferior, el Homo neanderthalensis, el Homo heidelbergensis de Mauer y el Eoanthropus de Piltdown. Con relación al «Hombre de Neanderthal» u Homo primigenius, decía que su existencia estaba bien documentada y que los descubrimientos de restos de este tipo fósil contradecían la opinión de Rudolf Virchow (1821-1902), J. Kollmann y J. Ranke. Estos anatomistas afirmaban, al igual que lo hacían Pujiula y su entorno, que desde la época de los glaciares los humanos no habían sufrido cambios en sus caracteres físicos y que el «hombre moderno» había aparecido con los rasgos actuales desde el momento de su aparición.

Por último, Obermaier se refería a los antropomorfos terciarios, considerando en este apartado al Pithecanthropus erectus. En este punto decía que dejaba a un lado la cuestión de relacionar directamente al Pithecanthropus con el árbol genealógico de la Humanidad. En su opinión, para seguir sosteniendo la suposición del parentesco directo de este género con el Homo, era necesario disponer de un cráneo entero con mandíbula que permitiera un estudio anatómico comparativo. Terminaba Obermaier manifestando que con los conocimientos actuales se podía afirmar que las diferencias entre humanos y antropomorfos no eran tan considerable como parecía al comparar los representantes actuales de ambos grupos. En efecto, decía Obermaier, se conocían tipos humanos fósiles no sólo más primitivos que las razas menos civilizadas del presente, sino que incluso algunos mostraban caracteres indiscutiblemente pitecoides ${ }^{35}$.

Este último comentario de Obermaier fue citado por Luis Mariano Vidal en la reseña realizada en la revista Ibérica de la monografía del prehistoriador

35 Obermaier, H. (1916), El Hombre fósil, Madrid, Museo Nacional de Ciencias Naturales, pp. 301-305. 
alemán. Señalaba también Vidal que Obermaier reconocía que no sería en las excavaciones paleontológicas de Europa en donde se hallaría la solución al problema de los orígenes de la Humanidad y aseguraba que no cabía duda del pensamiento evolucionista del autor de El Hombre fósil. Acababa Vidal afirmando que, aún admitiendo la evolución en cuestiones fitogeográficas y zoológicas aunque no para el origen del alma humana, había que respetar las ideas de los antropólogos, siempre que no pretendiesen establecer conclusiones que pudiesen ser arriesgadas, dado el estado del conocimiento sobre la Paleoantropología ${ }^{36}$.

De gran valor histórico para la Prehistoria y la Paleontología Humana fue el trabajo que leyó Manuel Antón en 1917, en su discurso de recepción en la Real Academia de la Historia. En una extensa memoria de ciento cuarenta y cinco páginas, Antón ofreció un completo panorama de los orígenes, en la década de los años sesenta del siglo XIX, y desarrollo histórico del debate sobre la existencia del «hombre terciario» y de la industria eolítica ${ }^{37}$.

Antón ya había mostrado su interés por la Paleoantropología siendo el primero que dio noticias en España del descubrimiento del Pithecanthropus erectus, a través de un artículo publicado en 1895 en la revista La Ilustración Española y Americana ${ }^{38}$. Las cincuenta últimas páginas de su trabajo como nuevo académico de la Historia, están dedicadas a la exposición de las tesis de Ameghino, a las controversias científicas que generaron la presentación del Pithecanthropus en la comunidad científica, y a los recientes hallazgos en Mauer y Piltdown. Terminaba diciendo que sólo dos formas humanas que no estaban bien determinadas, el Diprothomo y el Eoanthropus, parecían ser de edad terciaria. El Pithecanthropus y el Homo heidelbergensis se habían encontrado en terrenos plio-pleistocenos. Así que, decía, la industria eolítica se encontraba en sincronía con una forma incipiente de Humanidad en estado «eoantrópico». Esta fase estaba representada en Piltdown por una mandíbula «pitecoide» con dentición humana e implicaba la preparación artificial de las sustancias alimenticias, propias de un cerebro más inteligente y humano que el del Pithecanthropus, antropoide por su dentición y un eslabón anterior al «missing-link» de T.H. Huxley ${ }^{39}$.

\footnotetext{
36 VIDAL, L. M.(1916), El Hombre fósil, Ibérica, VI, 91-95.

37 ANTÓn FERrÁdiz, M. (1917), Los orígenes de la Hominación (Estudio de Prehistoria), Madrid.

38 Anton Ferrándiz, M. (1895), «¿El Anthropopithecus?», La Ilustración Española y Americana, n. XV, 247-250.

39 ANTÓN (1917), p. 142.
} 
Otra vía de comunicación de las ideas relacionadas con la Evolución Humana durante las primeras décadas del siglo XX fue Enciclopedia Universal Ilustrada, editada por Espasa, entre cuyos redactores y colaboradores se encontraron varios autores vinculados a la JAE, como Hernández Pacheco, Antón o Aranzadi. En las páginas de esta voluminosa obra se publicaron entre 1913 y 1930, diversas voces relacionadas con los hallazgos de restos fósiles humanos, como «Cromagnon $»^{40}$, «Grimaldi $»^{41}$, «Neanderthal» $»^{42}$, «Pitecantropo $\rangle^{43} \mathrm{o}$ 《Transformismo» ${ }^{44}$. En esta última voz se recogía el gran impacto que había tenido en la prensa descubrimiento del Australopithecus africanus en Sudáfrica, al ser considerado por su descubridor, Dart, un eslabón entre el hombre y los monos. Se lamentaba por el desliz en que habían caído ciertas revistas mundanas de París, Londres, Berlín y Madrid, al haber publicado un grabado imaginario del Australopithecus realizado por el especialista en este tipo de representaciones, Amedée Forestier.

\section{EPÍLOGO}

Durante la década de los años treinta siguieron publicándose en los apéndices y suplementos de la Enciclopedia Espasa, correspondientes a 1933, 1934 y 1935, voces como «Razas Paleolíticas», «Fósiles», o «Restos fósiles». Estas dos últimas aparecieron firmadas por Aranzadi dentro de una entrada más amplia dedicada a la Antropología, y en ellas el antropólogo vasco comentaba los últimos datos paleoantropológicos.

En 1933 en los valencianos «Cuadernos de Cultura» se publicó El origen de la raza humana de G. Schwalbe, obra de divulgación en el marco de una línea editorial republicana, que recogía las ideas de un antiguo y difunto antropólogo darwinista que había sido profesor de Anatomía en la Universidad de Estrasburgo.

40 «Cromagnón ó Cro-Magnón», Enciclopedia Universal Ilustrada Europeo-Americana,

T. 16, 1913, Barcelona, Hijo de J. Espasa Editores, 435-436.

41 «Grimaldi», Enciclopedia Universal Ilustrada Europeo-Americana, T. 26, 1925, Barcelona, Hijo de J. Espasa Editores, 1332.

42 «Neandertal (Raza de)», Enciclopedia Universal Ilustrada Europeo-Americana, T. 37, 1918, Barcelona, Hijo de J. Espasa Editores, 1459-1464.

43 «Pitecantropo», Enciclopedia Universal Ilustrada Europeo-Americana, T. 45, 1922, Barcelona, Hijo de J. Espasa Editores, 109-116.

44 «Transformismo», Enciclopedia Universal Ilustrada Europeo-Americana, T. 63, 1928, Barcelona, Hijo de J. Espasa Editores, 947-981. 
Asimismo, en estos años se difundieron en España a través de la Revista de Occidente las tesis anglosajonas sobre la evolución humana, basadas en el hallazgo del fósil de Piltdown. Sus autores, los neuroanatomistas A. Keith ${ }^{45}$ y G. Elliot Smith ${ }^{46}$, eran, como se ha visto, dos de los grandes referentes británicos de los estudios paleoantropológicos.

Con el inicio de la Guerra Civil en 1936, la actividad científica dirigida a actualizar el estado de los hallazgos y de las controversias sobre la Evolución Humana sufrió un comprensible proceso paralización, que no terminó hasta la finalización de la contienda. Atrás quedaban más de tres décadas a lo largo de las cuales la JAE había desarrollado su política científica destinada a fomentar la investigación en España.

45 KeIth, A. (1930), Últimos descubrimientos acerca del hombre fósil, Revista de Occidente, n. LXXXVI, 145-176.

46 Elliot Smit, G. (1933), La evolución del hombre, Revista de Occidente, n. CXXI, 1-41. 
